\title{
A study on cisplatin -paclitaxel induced peripheral neuropathy in cancer patients
}

\author{
Umamaheshwari C.*, Shanthi M., Malathi M.
}

Department of Pharmacology, Government Thiruvarur Medical College, Thiruvarur, Tamil Nadu, India

Received: 21 February 2019

Revised: 19 March 2019

Accepted: 28 March 2019

*Correspondence to:

Dr. Umamaheshwari C.,

Email: maheshwari200789@ gmail.com

Copyright: () the author(s), publisher and licensee Medip Academy. This is an openaccess article distributed under the terms of the Creative Commons Attribution NonCommercial License, which permits unrestricted noncommercial use, distribution, and reproduction in any medium, provided the original work is properly cited.

\begin{abstract}
Background: Chemotherapy induced peripheral neuropathy is a significant disability after the treatment of large number of cancers and they have an impact on quality of life. The aim of the present endeavour was to study the cisplatinpaclitaxel induced peripheral neuropathy in patients with lung or ovarian cancer Methods: The study was carried out in the Department of Oncology, Government Rajaji Hospital, Madurai, after obtaining clearance from Institutional ethical committee, Government Rajaji Hospital, Madurai. Thirty newly diagnosed patients suffering from Lung or ovarian cancer attending Oncology department were selected. After satisfying inclusion and exclusion criteria. Patient received injection cisplatin $60 \mathrm{mg} / \mathrm{m}^{2}$ and injection paclitaxel $175 \mathrm{mg} / \mathrm{m}^{2}$. Nerve conduction study was done to assess the peripheral neuropathy. It was done before starting the chemotherapy. Patients with grade 0 neuropathy were included for the study. Nerve conduction study was repeated after each cycle. The time taken to develop peripheral neuropathy was assessed using Cancer Institute Common Toxicity Criteria version 3.0. The data were analyzed with SPSS statistical software package (Version 16.0 SPSS Inc., Chicago, USA ).

Results: There is a statistically significant reduction in sensory nerve (sural) amplitude (SNAP) and latency $(\mathrm{p}<0.05)$ indicating significant axonal damage. The time taken to develop peripheral neuropathy was 3 cycles with grade $3 / 4$.

Conclusions: In this present study, the neurotoxicity induced by cisplatinpaclitaxel in patients with lung or ovarian carcinoma was observed, so that early intervention can prevent the permanent neurotoxicity.
\end{abstract}

Keywords: Cisplatin, Chemotherapy, Nerve conduction study, Neurotoxicity, Paclitaxel, Peripheral neuropathy

\section{INTRODUCTION}

Peripheral neuropathy is the most common neurological complication of cancer and cancer chemotherapy. ${ }^{1}$ Peripheral nervous system dysfunction in cancer patients is more common and it includes direct nerve compression by tumor or its infiltration; neurotoxicity of cancer treatment; nutritional deficiencies; metabolic derangements. ${ }^{2}$ It has been estimated that there are 28 million cancer survivors worldwide. $67 \%$ of patients outlast at 5 years. Assessing the long-term adverse effects of cancer chemotherapy is crucial due to their effect on cancer survivorship. Of particular importance is chemotherapy-induced peripheral neuropathy (CIPN), which may lead to permanent disability in $40 \%$ of cancer survivors. ${ }^{3}$ CIPN may be a significant disability after the treatment of large number of cancer, including breast, testicular, lung, ovarian, colorectal and hematological malignancies and have an impact on quality of life. Peripheral neuropathy is common in ovarian and lung cancer. The incidence of CIPN was found to be 21.5 in ovarian cancer and 18.3 in patients with lung cancer(per 1000 person-years) who received combination chemotherapy with Platinum-Paclitaxel. 54\% of patients after 6 cycles of chemotherapy and $23 \%$ after a median follow up of 18 months were found to have residual neuropathy. ${ }^{3} \quad$ Chemotherapy Induced Peripheral 
Neuropathy (CIPN) is an unmet clinical need in an approach to the cancer patients. More effective dosingschedules of treatment decreases the incidence of long lasting peripheral neurotoxicity thus providing better results with longer survival rate and less disability. ${ }^{4}$

Hence, a study was planned to assess the neurotoxicity of cisplatin-paclitaxel in patients with lung or ovarian carcinoma. So, that early intervention can prevent the permanent neurotoxicity.

\section{METHODS}

The study was carried out in the Department of Oncology and Department of Neurology Government Rajaji Hospital, Madurai, from December 2014 to June 2016 after obtaining clearance from Institutional ethical committee, Government Rajaji Hospital, Madurai. A Single center Open label Prospective Observational study carried out in 30 patients.

Drugs used were injection cisplatin $60 \mathrm{mg} / \mathrm{m}^{2}$, injection paclitaxel $175 \mathrm{mg} / \mathrm{m}^{2}$. All the patients received premedications consisting of single dose of dexamethasone $(20 \mathrm{mg})$ and ranitidine $(50 \mathrm{mg})$ administered 30 minutes before start of Paclitaxel infusion and anti emetic prophylaxis with ondansetron . In addition, patients received pre and post chemotherapy hydration to avoid cisplatin induced nephrotoxicity. Chemotherapy cycles were repeated every 3 weeks.

\section{Inclusion criteria}

- Newly diagnosed patients with lung or ovarian cancer,

- Age group: 18 to 60 years,

- Patients with grade 0 peripheral neuropathy (National Cancer Institute - Common Toxicity Criteria version 3.0.).

\section{Exclusion criteria}

- Those with pre-existing peripheral neuropathy,

- Patients with any other comorbid conditions,

- Patients with extensive CNS metastasis,

- Pregnancy and breastfeeding patients,

- When the patient was found to develop another illness or worsening of existing illness or requiring additional drugs, they were withdrawn from the study

The study was carried out in 30 patients who satisfied the inclusion /exclusion criteria after getting written and informed consent.

\section{Investigations}

Complete haemogram, blood sugar, renal function test, liver function test, thyroid profile, nerve conduction studyto assess the peripheral neuropathy, nerve conduction study was done before starting the chemotherapy. Patients with grade 0 neuropathy were included for the study
Patients were followed up after each cycle till the end of 6 cycles and examined for signs and symptoms of peripheral neuropathy. Nerve conduction study was repeated after each cycle. Time taken by each group to develop peripheral neuropathy were assessed using Cancer Institute - Common Toxicity Criteria version 3.0.

\section{Statistical analysis}

The data were analyzed with SPSS statistical software package (Version 16.0 SPSS Inc., Chicago, USA). The nerve conduction study variables were compared before and after chemotherapy using students t test and $\mathrm{p}<0.05$ will be considered as statistically significant.

\section{RESULTS}

All the patients were reviewed once in three weeks and there was no drop out in the study, all the 30 patients were analyzed for the time taken to develop neuropathy. Among thirty patients analyzed $(30 \%)$ were males and rest were females (70\%), The age wise distribution was 7 (23\%) patients belonged to 30-39 years, $17(57 \%)$ were between 40-49 years, $6(20 \%)$ belonged to 50-59 years. The tumor type includes $(33 \%)$ were mucinous cystadenoma ovary, $(33 \%)$ were serous cyst adenocarcinoma, (14\%) were nonsmall cell carcinoma, (20\%) were squamous cell carcinoma. The mean latency of sural nerve before and after chemotherapy were $3.547 \pm 0.44$ and $6.493 \pm 0.734$. The mean amplitude of sural nerve before chemotherapy was $8.267 \pm 0.928$ and $3.980 \pm 0.728$ after they developed neuropathy (Figure 1).

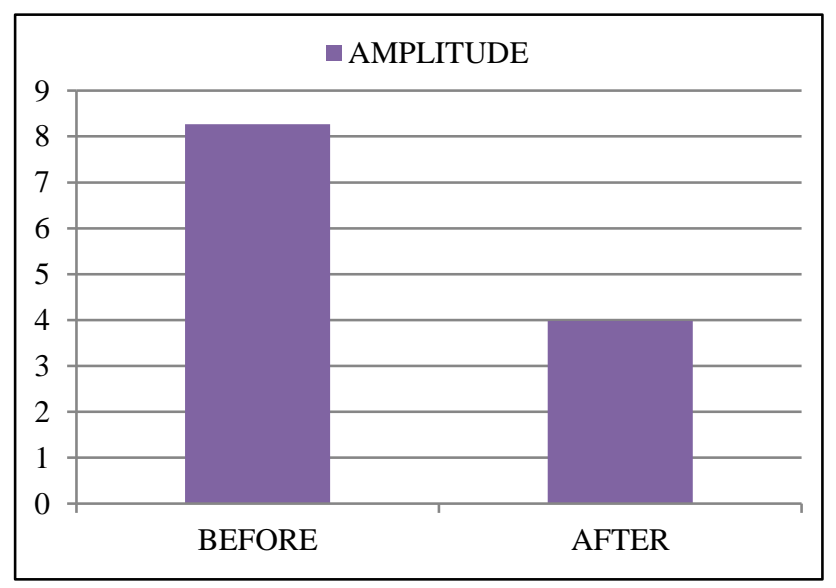

Figure 1: Amplitude of sural nerve.

The conduction velocity of sural nerve before chemotherapy was $45.63 \pm 3.00$ and was $48.73 \pm 2.84$ after they developed neuropathy. The mean latency of peroneal nerve before chemotherapy was $3.760 \pm 0.3233$ and latency was $3.983 \pm 0.3495$ after they developed neuropathy .The mean amplitude of peroneal nerve before chemotherapy was $3.577 \pm 0.6579$ and $3.360 \pm 0.6532$ after they developed neuropathy. The conduction velocity of peroneal nerve before chemotherapy was $46.50 \pm 2.146$ and was $49.4 \pm 2.2$ after they developed neuropathy (Figure 2). 


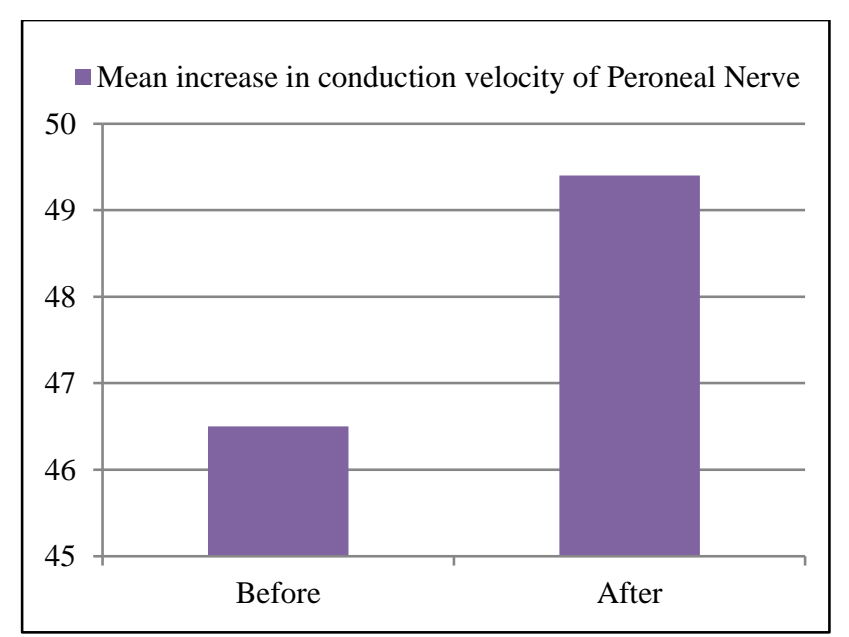

Figure 2: Conduction velocity of peroneal nerve.

The nerve conduction study variables were compared before and after neuropathy using students t test and the results were statistically significant $(\mathrm{p}<0.05)$ imparting that there was significant difference before and after chemotherapy (Table 1). The time taken to develop peripheral neuropathy was $3.36 \pm 0.71$ cycles. The grading of peripheral neuropathy was found to be grade III.

Table 1: Comparison of nerve conduction study variables before chemotherapy and after they developed neuropathy cisplatin-paclitaxel group.

\begin{tabular}{|lll|}
\hline Sural Nerve & $\begin{array}{l}\text { Before } \\
(\text { Mean } \pm \text { SD) }\end{array}$ & $\begin{array}{l}\text { After } \\
(\text { MEAN } \pm \text { SD) }\end{array}$ \\
\hline Latency & $3.547 \pm 0.44$ & $6.493 \pm 0.734^{*}$ \\
\hline Amplitude & $8.267 \pm 0.928$ & $3.980 \pm 0.728^{*}$ \\
\hline $\begin{array}{l}\text { Conduction } \\
\text { velocity }\end{array}$ & $45.63 \pm 3.00$ & $48.73 \pm 2.84^{*}$ \\
\hline Peroneal nerve & $\begin{array}{l}\text { Before } \\
\text { (Mean } \pm \text { SD) }\end{array}$ & $\begin{array}{l}\text { After } \\
\text { (Mean } \pm \text { SD) }\end{array}$ \\
\hline Latency & $3.760 \pm 0.3233$ & $3.983 \pm 0.3495^{*}$ \\
\hline Amplitude & $3.577 \pm 0.6579$ & $3.360 \pm 0.6532^{*}$ \\
\hline $\begin{array}{l}\text { Conduction } \\
\text { velocity }\end{array}$ & $46.50 \pm 2.146$ & $49.4 \pm 2.2^{*}$ \\
\hline
\end{tabular}

$* \mathrm{p}$ value $<0.05$

\section{DISCUSSION}

The peripheral nervous system is affected more than central nervous system because it is not protected as effective as central nervous system from noxious exogeneous agents. ${ }^{5}$ Drug-induced neurotoxicity can affect the nerve fibers or the dorsal root ganglia (DRG) of the primary sensory neurons. ${ }^{6}$ The clinical features are dependent on the type of agent involved and its site of action. Chemotherapy-induced peripheral neuropathy is related to treatment schedules and concomitant drugs. ${ }^{7}$ It may severely affect the quality of life of cancer patients and cause chronic discomfort. In this present study, the neurotoxicity induced by cisplatin-paclitaxel in patients with lung or ovarian carcinoma was observed, so that early intervention can prevent the permanent neurotoxicity. ${ }^{8}$ when nerve conduction variables are compared before and after chemotherapy there is a significant reduction in sensory nerve (sural) amplitude (SNAP) and latency ( $p$ $<0.05$ ) indicating significant axonal damage. In a randomized study by Daugaard GK et al, nerve conduction studies performed in patients treated with platinum drugs showed sensory axonal damage with reduction in amplitude of the sensory nerve action potentials (SNAP). Motor nerve conduction velocities (NCV), compound muscle action potentials (CMAP) and F-wave latencies remain unchanged during treatment. ${ }^{9}$ In a study by Windebank AJ et al, Electrophysiological abnormalities were decrease in SNAP indicating axonal sensory peripheral neuropathy. Reduction of CMAP occurs at the highest cumulative doses, while sensory and motor NCV are usually spared. ${ }^{10}$ In this study, the time taken to develop peripheral neuropathy in cisplatin-paclitaxel group was 3 cycles. The occurrence of sensory neuropathy (which is proved by reduction in sensory nerve amplitude seen in nerve conduction study) is most commonly encountered than motor neuropathy. Since this is an observational study, dose relationship could not be explained for the development of adverse effects So, further studies are needed to confirm the dose adjustment for the reduction of neurological manifestations.

Funding: No funding sources Conflict of interest: None declared

Ethical approval: The study was approved by the Institutional Ethics Committee (13432/E1/8/2014)

\section{REFERENCES}

1. Dropcho EJ. Remote neurological manifestations of cancer. Neurologic Clin. 2002;20(1)85-122.

2. Jaman $\mathrm{P}$, Neurological disease peripheral nerve disease. In:Parveenkumar \& Michaelclark. Kumar \& clark clinical medicine. 8th ed. Spain: Saunders Elsevier;2012:148.

3. Nurgalieva Z, Xia R, Liu CC, Burau K, Hardy D, Du XL, Risk of chemotherapy-induced peripheral neuropathy in large population-based cohorts of elderly patients with breast, ovarian, and lung cancer. Am J Ther. 2010 Mar-Apr;17(2):148-58.

4. Leach JP, Davemport RJ disease of peripheral neuropathy, neurological disease. In: Brain R. Walker. Davidsons principle \& practice of medicine. 22nd ed. China: Lippincott Williams \& Wilkins Elsevier; 2015:1223-1226.

5. Eric P Widmaier, Hershal Raff. Neural signalling and the structure of nervous system in Vanders Human physiology. 11th ed. New York: McGraw hill; 2008:138.

6. Hilkens PH, Pronk LC, Verweij J, Vecht CH, Van Putten WL, Van Den Bent MJ. Peripheral neuropathy induced by combination chemotherapy of docetaxel and cisplatin. Brit J Canc. 1997 Feb;75(3):417.

7. Lisa M, De Angelis, Patrick y Wen, Primary and metastatic tumors of the nervous system In:Longo, 
fauci. Harrisons Neurology in Clinical medicine. 3rd edition. China: McGraw Hill; 2013:438.

8. Argyriou AA, Bruna J, Marmiroli P, Cavaletti G. Chemotherapy-induced peripheral neurotoxicity (CIPN): an update. Crit Rev Oncol Hematol. 2012 Apr 1;82(1):51-77.

9. Daugaard GK, Petrera J, Trojaborg W. Electrophysiological study of the peripheral and central neurotoxic effect of cis-platin. Acta Neurologica Scandinavica. 1987;76(2):86-93.
10. Grisold W. Chemotherapy-induced neuropathy. J Peripher Nerv Syst. 2008;13(1):27-46.

Cite this article as: Umamaheshwari $\mathrm{C}$, Shanthi $\mathrm{M}$, Malathi M. A study on cisplatin -paclitaxel induced peripheral neuropathy in cancer patients. Int $\mathbf{J}$ Basic Clin Pharmacol 2019;8:977-80. 